\section{P.1.06 EFFECTS OF CIGARETTE SMOKING ON HEARING LOSS IN WORKERS WITH NOISE EXPOSURE}

${ }^{1}$ Po-Ching Chu*, ${ }^{2}$ Mrs Carrie Hsu. 'National Taiwan University and National Taiwan University Hospital, Taipei, Taiwan; ${ }^{2}$ Powertech Technology Inc., Hsinchu, Taiwan

\subsection{6/OEM-2019-EPI.212}

Objectives Previous studies found that noise and cigarette smoking are risk factors of hearing loss. This study aimed to investigate effects of cigarette smoking and other factors on hearing loss.

Methods This was a cross-sectional study of 95 machine maintenance workers with noise exposure in an electronics industry. The databases of health examination and environmental monitoring were used, and the information on demographics, years of employment, habit of cigarette smoking, hearing levels of pure tone audiometry, and levels of personal noise exposure monitoring (TWA) were assessed. There were two definitions of hearing levels, which were the mean level (mean of bilateral $3 \mathrm{~K}, 4 \mathrm{~K}, 6 \mathrm{~K} \mathrm{~Hz}$ ) and the maximal level (maximum of bilateral $3 \mathrm{~K}, 4 \mathrm{~K}, 6 \mathrm{~K} \mathrm{~Hz}$ ). Linear regression was applied to explore the association.

Results $60.0 \%, 14.7 \%$, and $25.3 \%$ workers were never smokers, ever smokers who had quit, and current smokers, respectively. The multivariable linear regression showed that current smokers had higher mean hearing level than never smokers $(\beta=4.54,95 \% C I=-0.10-9.19)$; age was associated with the mean hearing level $(\beta=0.52,95 \% \mathrm{CI}=0.25-0.79)$. In additions, another multivariable model showed that current smokers had higher maximal hearing level than never smokers $(\beta=8.36$, 95\% CI=0.28-16.43); age was associated with the maximal hearing level $(\beta=0.91,95 \% \mathrm{CI}=0.45-1.38)$. Years of employment and noise exposure levels were not associated with hearing levels. Concerning workers aged 36 years or older, subgroup analysis found that the maximal hearing levels were $25 \mathrm{~dB}$ (never smokers), ever smokers who had quit $(30 \mathrm{~dB})$, and current smokers $(45 \mathrm{~dB})$, which had statistical significant $(\mathrm{p}=0.048)$.

Conclusions The findings suggest that old age and current smoking were risk factors of hearing loss, and also call attention to the importance of preventing hearing loss including quitting smoking for noise exposure workers.

\section{P.1.07 A STUDY OF BLOOD MULTI-ELEMENT CONCENTRATIONS IN LEAD-EXPOSED AND NON- EXPOSED WORKERS}

\footnotetext{
1,2Hung-Yi Chuang*, 'Ya-Han Shen. 'Kaohsiung Medical University, Kaohsiung City, Taiwan; ${ }^{2}$ Kaohsiung Medical University Hospital, Kaohsiung City, Taiwan
}

\subsection{6/OEM-2019-EPI.213}

Objectives Although the leaded gasoline has been phased out, lead $(\mathrm{Pb})$ continues to be a public health concern due to its widely industrial uses. During the lead industrial processes, these workers exposed to the other non-essential elements, which can induce adverse effects including the imbalance of essential elements. The aim of this study is to compare with $\mathrm{Pb}$, cadmium (Cd), arsenic (As), selenium (Se), cobalt (Co), copper $(\mathrm{Cu})$, zinc $(\mathrm{Zn})$ in human whole blood between leadexposed and non-exposed workers.

Method There were 109 lead workers and 329 individuals of non-exposed group, received the health examination in Kaohsiung Medical University Hospital, Taiwan. The whole blood concentration of $\mathrm{Pb}$ was determined by graphite atomic absorption spectrometer (AAS), while the others (Cd, As, Se, $\mathrm{Co}, \mathrm{Cu}$ and $\mathrm{Zn}$ ) were determined by inductively coupled plasma mass spectrometer (ICPMS). We analyzed the associations between the seven elements and the worker health examination data. Finally, multiple linear regressions were used to analyze interaction between elements.

Results For all workers, the average of age was 40.13 years and mean BMI was 24.81. The other health examination results showed the well status of health and nutrition. Mean concentrations of seven blood elements in Pb-exposed workers were $\mathrm{Pb}=143.5, \mathrm{Cd}=1.28, \mathrm{As}=9.45, \mathrm{Se}=251.46, \mathrm{Co}=0.57$, $\mathrm{Cu}=1044.4$, and $\mathrm{Zn}=9706.92(\mathrm{ug} / \mathrm{L})$. On the other hand, the blood concentrations of these elements in non-exposed workers were $\mathrm{Pb}=26.18, \mathrm{Cd}=0.98, \quad \mathrm{As}=5.28, \quad \mathrm{Se}=255.40$, $\mathrm{Co}=0.42, \mathrm{Cu}=880.07$, and $\mathrm{Zn}=6891.52 \quad(\mathrm{ug} / \mathrm{L})$. Using the interaction variables, the results showed that there were interactions between $\mathrm{Cd}$ and $\mathrm{As}$, As and $\mathrm{Co}$, As and $\mathrm{Cu}$.

Conclusions The positive effect of essential elements to health examination values were not clear, little does the influence to the other non-essential elements. However, the damage from occupational non-essential elements exposure still needs to be concerned. Interaction to multi-elements also needs further research.

\section{P.1.08 CONNECTING CONTRACTOR SAFETY MANAGEMENT PROGRAMS AND WORKER PERCEIVED SAFETY CLIMATE IN COMMERCIAL CONSTRUCTION PROJECTS}

Ann Marie Dale*, Skye Buckner-Petty, Bradley Evanoff. Washington University School of Medicine - General Medical Sciences, St. Louis, USA

\subsection{6/OEM-2019-EPI.214}

Background Leading indicators are preferred to identify injuries and fatalities in construction industry. Safety climate is a leading indicator of construction injuries yet it is not known how workers' safety climate scores relate to safety programs of different maturity levels.

Methods This study examined the relationship between safety program scores based on documents and contractor reported activities and project leading indicators of contractor safety climate, safety behaviors of workers and crews, and safety attitudes of coworkers from employee surveys. Hierarchical linear regression models accounted for contractor size and number of workers, nested in contractors within projects. Separate models examined the relationships between safety program scores and 1) contractor safety climate; 2) coworker attitude scores, 3) employees' own behavior score, and 4) crew behavior scores.

Results 446 employees of 40 contractors from three commercial construction projects participated. Many contractors $(n=16)$ had good safety programs with 15 or more safety activities (out of 17) from organizational management, worker participation, hazard identification, and training domains. Stronger safety programs had higher safety climate scores (5.15 point difference on a 100 point scale, $\mathrm{p}=0.05)$, better coworker safety attitudes (6.69 points, $\mathrm{p}=0.01)$, better crew safety behaviors (5.34 points, $\mathrm{p}=0.02)$ and higher self-rated behaviors $(5.14$ points, $\mathrm{p}=0.02)$ compared to safety programs with fewer safety items.

Conclusions Contractors with more comprehensive safety programs were perceived to have stronger safety climate. Better 